\title{
The impact of location of 3D printers and robots on the supply chain
}

\author{
Shunichi Ohmori ${ }^{\mathrm{a}^{*}}$
}

\begin{tabular}{l}
${ }^{a}$ Waseda University, Japan \\
\hline C H R O N I C L E \\
\hline Article history: \\
Received November 28,2020 \\
Received in revised format \\
January, 7, 2021 \\
Accepted January 72021 \\
Available online \\
January 72021 \\
\hline Keywords: \\
3D printing, supply chain \\
Safety stock placement \\
Multi-echelon inventory \\
optimization
\end{tabular}

\begin{abstract}
A B S T R A C T
3D printers and robots (3DPR) are new technologies that may disrupt traditional supply chains. The location of the manufacturing place can be moved toward more customer side in the supply chain, which brings both agility and the ability of customization. The impact is yet to be examined quantitatively. In this paper we study the location of 3DPR in the supply chain. We present and compare three models of supply chains: Traditional supply chain; 3DPR at warehouse; 3DPR at shop. The semodels are compared by the equipment installation cost, the production cost,and inventory cost for safety-stock. The study presents a practical case study motivated from a real-world apparel company, discusses the three models under various parameter settings, comparing the obtained total cost and discovers the advantages and disadvantages.
\end{abstract}

(C) 2021 by the authors; license Growing Science, Canada.

\section{Introduction}

Recentadvancement in emerging technologies like 3D printers and robots (3DPR) opensup new opportunities in manufacturing. 3D printers (3DP) are known as additivemanufacturing, rapid manufacturing or direct digital manufacturing (Khajavi etal., 2014; Holmström et al., 2010; Sasson \& Johnson, 2015; Rogers et al.,2016). It is a disruptive and innovative technology that may change supplychains (Halassi et al., 2018). This technology has beenrapidly applied in many industries such as the apparel industry and service partsfor the electronic industry. The advantages of using 3DPfrom a manufacturing and supply chain point of view, has been widely discussedin the past literatures. For example, Holmström et al.'s (2014) opinions on theadvantages of using 3DP have been widely cited: (1) No tooling is neededsignificantly reducing production ramp-up time and expense; (2) Smallproduction batches are feasible and economical; (3) Possibility to quicklychange design; (4) Allows product to be optimized for function; (5) Allowseconomical custom products (batch of one); (6) Possibility to reduce waste; (7)Potential for simpler supply chains; shorter lead times, lower inventories; (8)Design for customization.

\section{Table 1}

portion of push and pull supply chain with 3DPR

\begin{tabular}{ccc}
\hline Portion & Push & Pull \\
Unit production cost & Low & High \\
Inventory across a supply chain & Low & High \\
Outbound Leadtime & Long & Short \\
Number of stock points & More & Less \\
Number of 3DPRs & Less & More \\
\hline
\end{tabular}

As with always the case with new technologies, however, it brings notonly new opportunities but also new challenges for manufacturers, who will needto strategically integrate a wholly new supply chain model into theiroperations (Sohdi \& Tang,

\footnotetext{
* Corresponding author

E-mail address: ohmori0406@aoni.waseda.jp (S. Ohmori)

(C) 2021 by the authors; licensee Growing Science.

doi: $10.5267 /$ j.uscm.2021.1.002
} 
2017; Tang \& Veelenturf 2019). Especially,the location of 3DPR forms a basis for supply chain characteristics and significantlyimpacts the efficiency of the supply chain. Traditionally, manufacturing ismade only in factories. However, 3DPR can be installed in warehouses or shops asin Fig. 1. By doing so, the push-pull boundary is forward to the customer side. Thisentails push-pull supply chain trade-off as summarized in Table 1.

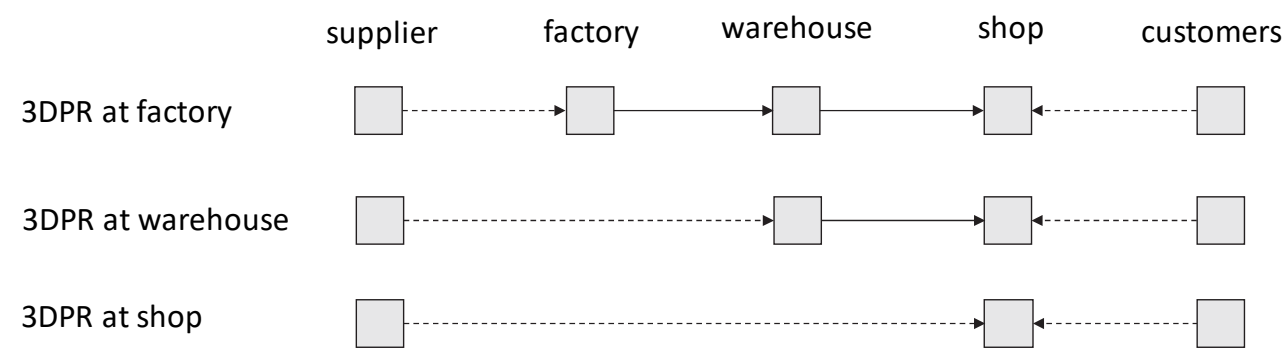

Fig. 1. Potential locations for 3DPR in a supply chain

Traditionally, Fisher (1997) addresses the issue of matching products and supply-chains and has become the milestone of designing supply chains ever since. He categorized supply chain strategies as either the physically-efficient supply chain, sometimes referred to as a push strategy, or the market-responsive supply chain, sometimes called a pull strategy. The primary purpose of the push strategy is to supply forecasted demand efficiently at the lowest possible cost. Whereas, the purpose of the pull strategy is to respond quickly to actual demand in order to minimize stock outs, forced markdowns, and obsolete inventory. He proposed two different types of goods, namely, functional products and innovative products. Functional products satisfy basic needs, which do not change much over time, they have stable, predicable demand, long life cycles, and low profit margins. Examples include products that people buy in a wide range of retail outlets, such as diapers, milk, and tires. Innovative products are associated with fast product-innovation speed, unpredictable demand, and high profit margins. Typical examples in this category include fashion products, cosmetics, or high-tech products. He claimed that the right supply chain for the functional products is the push strategy, and the one for the innovative products is the pull strategy.

The principlesand trade-off on designing push-pull boundaries in Fischer (1997) still work intheory up to present. The efficient design of supply chain with 3DPR is a majorchallenge for many companies, given a number of factors and interactionsinvolved. Sodhi and Tang (2018) called 3DPR as third-option, as it disruptstrade-offs. Few papers examine this new issue quantitatively.

This paper studies the location of 3DPR in the supply chain and presents and compares three models of supply chains: Traditional supply chain; 3DPR at warehouse; 3DPR at shop. These models are compared by the equipment installation cost, the production cost and inventory cost for safety-stock. The inventory cost for safety-stock is obtained by the guaranteed-service model proposed by Graves and Willems (2000). We present a practical case study motivated from a real-world apparel company. We discuss the three models under the different parameter settings, comparing the obtained total cost. By doing so, we discover the advantages and disadvantages.

Remainder of research is as follows. In section 2, we review related research. In section 3, we present the proposed modeling framework. In section 4, we present numerical experiments and managerial implications. In section 5, we make concluding remarks and future work.

\section{Literature review}

\subsection{3 printer and robotics}

There are many publications to introduce 3DPR (Eyers \& Dotchev, 2010; Berman, 2012; Lipson \& Kurman, 2013; Fawcett \& Waller, 2014; Gao et al., 2015; Rayna et al., 2015; Rayna \& Striukova 2016). These papers discuss potential benefits of 3DPR from a manufacturing perspective, such as cost-effectiveness, tooling, quality and modularity. The barriers for application are also well discussed topics. One well discussed topic is energy consumption and CO2 emission. On one hand, it reduces the excess production (Gebler et al., 2014). On the other hand, energy consumption of additive processes is higher than that of conventional bulk-forming processes (Yoon et al., 2015). Legal issues, such as data management and intellectual property protection, are also discussed topics, as it is one of the barriers for industries to apply. Rideout (2011) studied the copyright implications of 3DP. Doherty 2012 claimed that patent law was a roadblock to the 3D printing revolution.

The impact of 3DPR on supply chain strategy has been widely discussed in recent years (Holmström et al., 2014). Of many advantages of 3DPR, the capability of customization is the most discussed topic (Eyers \& Dotchev 2010, Fandel et al., 2012; Wieland et al., 2012, Rayna et al., 2015, Petrick \& Simpson 2013). The location of manufacturing is moved towards more customer side (D'Aveni, 2013; Mellor et al., 2014; Gebler et al., 2014; Khajavi et al., 2014). As a result, the number of intermediate suppliers is expected to be decreased (Mellor et al., 2014; Christopher \& Ryals 2014). The production can 
be on a made-to-order basis. Postponement or delayed differentiation are made possible and more customization can be achieved at a lower cost. The outbound lead time becomes shorter. The inventory is reduced due to the better anticipating incoming orders. These advantages discussed above are advantages of pull-based supply chain (Simchi-Levi, 2010).

Most of the above cited research discusses the opportunity and challenge to use 3DPR qualitatively. The impact is yet to be examined quantitatively. Due to the large number of factors influencing the optimal setup, however, profound quantitative analysis is required to exploit its full potential. This research makes the contribution by validating the issues addressed in the paper quantitatively. We analyzed the implications of locating 3DPR at warehouses and shops, at the tactical level of decision-making. We present a mathematical model and compare the supply chain configurations with respect to the location of 3DP under different parameter settings and discuss when, how much and why one configuration is better than each other. Considering the quantitative implications jointly, the analysis provides a valuable tool to support rational decision-making and implementation in practice.

\subsection{Strategic safety stock placement}

Themodels presented in the paper are compared by the equipment installation cost, the production cost and inventory cost for safety-stock. Among such, theequipment installation cost and the production cost can be calculated by thesimple multiplication. To calculate the inventory cost, however, one needs thetactical decision on where and how much inventory in the multi-echelon supply chain, out of a large combination of alternatives. This entails the multi-echeloninventory optimization, called the strategic safety stock placement problem. Inthis section, we review the strategic safety stock placement problem. The strategic safety stock placement problem is a tactical modelto determine the amount and positioning safety stocks in supply chains. Therehas been growing opportunities to optimize supply-chains in a global manner, due to the rapid progress of information technology. One of the most attractiveareas among the supply chain optimization is to minimize inventory over theentire supply chain. Many real-world supply-chains are multi-echelon systemsthat consist of several stages, where each stage has millions of dollars ofinventory to protect the system against stock-outs. Often in practice, it isdifficult for managers to manage thousands of SKUs with different demandcharacteristics, and thus, needs to optimize with mathematical-programmingtechniques has been emerging. There are two research streams, namely, the Stochastic-service (SS) model and the Guaranteed-service (GS) model. Particularly, the GS modelhas taken a growing interest to both academia and practice in the past twodecades, as it is a simple, easily accessible model, run on personal computers. There have been extensive model expansions for thestrategic safety stock placement model (See Topan et al., (2020) for the review). The original model dates back to Clark and Scarf (1960) for a serial supplychain. Graves and Willmes (2000) proposed the model for the spanning tree. Gravesand Willems (2008), Neale and Willems (2009) proposed the GS model for non-stationarydemand, Schoenmeyr \& Graves (2009) consider evolving demand forecasts, Inderfurth (1993) proposed a model to incorporate stochastic lead-times, Sitompulet al., (2008), Schoenmeyr (2008) proposed capacity constraints, Li and Chen (2012) proposed a model under the continuous-review batch ordering policy. Graves and Schoenmeyr (2016) proposed a strategic safety-stock placement in supply chains withcapacity constraints with inner queue.

There are many industrial applications as automotive (Moncayo-Martínez et al., 2014; Rambau \& Schade 2014), computer hardware (Billington et al., 2004; Graves \& Willems 2005; Li \& Womer 2008, Graves \& Willems, 2005; Neale \& Willems 2009), consumer goods (Farasyn et al., 2011, Humair et al., 2013), digital imaging (Graves \& Willems, 2000), electronic test equipment (Schoenmeyr \& Graves, 2009), industrial chemicals (Bossert \& Willems, 2007; You \& Grossmann, 2008; You \& Grossmann, 2011; Humair et al., 2013; Ni \& Shu 2015), industrial electronics (Klosterhalfen et al., 2014), machinery (Graves and Willems 2003, Neale and Willems 2009, Funaki 2012), metal mechanics (Moncayo-Martínez \& Zhang 2013), semiconductor (Tian et al., 2011; Wiel et al., 2012).

The mathematical model presented in this paper is based on the guaranteed service model. Our paper is the application of the model in the new business context. In most of the models presented in the above cited papers the strategic safety stock placement problem is solved under a given supply network. On the other hand, we compare and discuss the advantages and disadvantages of the different supply networks under different parameter settings.

\section{The proposed model}

The following section describes the modeling framework based on the GS model. Section 3.1 presents a summary of the notation, section 3.2 presents the general strategic safety stock placement problem following that of Graves \& Willems (2000), section 3.3 presents the specific formulation for the traditional supply chain, the 3DPRW and the 3DPRS.

\subsection{Notation}

The summary of notation is presented as follows:

- $\quad N$ : A set of stages

- $\quad N_{d}$ : A set of leaf-nodes (external customers)

- $\quad N_{m}$ : A set of source-nodes (external material suppliers) 
- $A$ : a set of arcs

- $\mu_{i}$ : the average demand for stage $i$

- $\quad \kappa$ : Safety factor

- $\sigma_{i}$ : the standard deviation of demand for stage $i$

- $\phi_{i j}$ : the number of units of the upstream component $j$ required per downstream unit $i$

- $d_{i t}$ : demand for stage $i$ at period $t$

- $\quad s_{i}^{i n}:$ in-bound service time at stage $i$

- $\quad s_{i}^{\text {out }}$ : guaranteed service time at stage $i$

- $\quad s_{i}$ : required lead - time from external customer

- $\quad D_{i}(\tau)$ : maximal demand during time interval during $\tau$

- $\quad B_{i}$ : base-stock level of stage $i$

- $\quad T_{i}$ : service level target for external customer $i \in N_{d}$

- $s_{i}$ : service level target quoted by external supplier $i \in N_{s}$

- $n_{p}$ : number of products

- $n_{w}$ : the number of warehouses

- $n_{s}$ : the number of shops connected by one warehouse

- $n_{p}$ : the number of product types

- $\quad N_{f} \subseteq N=\left\{i \mid i=1, \cdots, n_{p}\right\}$ : a factory node

- $N_{w} \subseteq N=\left\{i \mid i=n_{p}+1, \cdots, n_{p} \times\left(1+n_{w}\right)\right\}$ : a set of warehouse nodes

- $N_{s} \subseteq N=\left\{i \mid i=n_{p} \times\left(1+n_{w}\right)+1, \cdots, n_{p} \times\left(1+n_{w}\right)+n_{p} \times n_{w} \times n_{s}\right\}$ denote a set of shop nodes.

- $\quad s_{f}^{\text {in }}$ : the inbound service time of factory nodes

- $s_{f}^{o u t}$ : the outbound service time of factory nodes

- $h_{f}$ : the inventory holding cost for the factory node

- $\sigma_{f}$ : the standard deviation of demand for the factory node

- $\quad p_{f}$ : the processing time at the factory node

- $\quad s_{w}^{i n}$ : the inbound service time of warehouse nodes

- $s_{w}^{\text {out }}$ : the outbound service time of warehouse nodes

- $\quad h_{w}$ : the inventory holding cost for the warehouse node

- $\sigma_{w}$ : the standard deviation of demand for the warehouse node

- $\quad p_{w}$ : the processing time at the warehouse node

- $s_{s}^{\text {in }}$ : the inbound service time of shop nodes

- $s_{S}^{\text {out }}$ : the outbound service time of shop nodes

- $h_{s}$ : the inventory holding cost for the shop node

- $\sigma_{s}$ : the standard deviation of demand for the shop node

- $p_{s}$ : the processing time at the shop node

- $C_{f}$ : the total cost of the traditional supply chain

- $C_{f}^{E}$ : the equipment installation cost of the traditional supply chain

- $\quad C_{f}^{P}$ : the production cost of the traditional supply chain

- $\quad c_{f}^{p}$ : the unit production cost of the traditional supply chain

- $\quad C_{f}^{I}$ : inventory holding cost of the traditional supply chain

- $C_{w}$ : the total cost of the 3DPRW supply chain

- $\quad C_{W}^{E}$ : the equipment installation cost of the 3DPRW supply chain

- $\quad C_{w}^{P}$ : the production cost of the 3DPRW supply chain

- $\quad c_{w}^{p}$ : the unit production cost of the 3DPRW supply chain

- $\quad C_{w}^{I}$ :inventory holding cost of the 3DPRW supply chain

- $C_{S}$ : the total cost of the 3DPRS supply chain

- $C_{S}^{E}$ : the equipment installation cost of the 3DPRS supply chain

- $C_{S}^{P}$ : the production cost of the 3DPRS supply chain

- $\quad c_{s}^{p}$ : the unit production cost of the 3DPRS supply chain

- $\quad C_{S}^{I}$ :inventory holding cost of the 3DPRs supply chain

\subsection{Guaranteed service model of safety stock placement}

Network

A supply chain is modeled as a spanning-tree network of stages, where each stage represents a necessary function, such as procurement, assembly, or transportation. Let $N$ denote a set of stages and $N_{d}$ denote a set of leaf-nodes (external customers) and $N_{m}$ denote a set of source-nodes (external suppliers). Let $A$ denote a set of arcs. Each stage operates according to a periodic review policy with a common review period. 
Let $\phi_{i j}$ denote the number of units of the upstream component $j$ required per downstream unit $i, \mu_{i}$ denote the average demand for stage $i, d_{i t}$ denote demand for stage $i$ at period $t$. The demand at upstream stage $j$ in period $t$ and the average demand at stage $j$ is:

$d_{j t}=\sum_{i, j \in A} \phi_{i j} d_{i t}$,

$\mu_{j}=\sum_{i, j \in A} \phi_{i j} \mu_{i}$.

The key assumption of the GS model is that demand is bounded to make the service-time guarantee. The demand at stage $i$ for $\tau$ periods is bounded by $D_{i}(\tau)$ as

$D_{i}(\tau) \geq d_{i t}+\cdots+d_{i(t-\tau-1)}$

$D_{i}(\tau)$ is assumed as increasing and concave function with $D_{i}(0)$. If the demand follows the normal distribution, i.e. $d_{i t} \sim$ $\mathcal{N}\left(\mu_{i}, \sigma_{i}^{2}\right), D_{i}(\tau)$ can be defined as

$D_{i}(\tau)=\tau \mu_{i}+\kappa \sigma_{i} \sqrt{\tau}$

\section{Guaranteed Service Time}

In the GS model, each stage $i$ can quote a guaranteed-service time $s_{i}^{\text {out }}$ that it can always satisfy to its customer stages. Demand order $d_{i t}$ must be filled by time $t+s_{i}^{o u t}$. Each stage $i$ must hold sufficient inventory so that it can always satisfy the $100 \%$ service-time commitment. Such a commitment can be accomplished with a finite stock of inventory due to the bounded demand assumption.

\section{Periodic-Review Base-Stock Replenishment Policy}

Each stage operates according to a periodic review policy with a common review period. The order policy at each stage is base-stock policy. Each stage $i$ has a base-stock level $B_{i}$. Each stage $i$ observes demand $d_{i t}$ at period $t$ and places a replenishment order $u_{i t}=d_{i t}$. This can be interpreted as a special case of $(s, S)$ policy as $\left(B_{i}, B_{i}\right)$.

Inventory dynamics of stage $i$ under base-stock policy is written as in Eq. (1).

$$
I_{i k t}=I_{i k(t-1)}-d_{i\left(t-s_{i}^{o u t}\right)}+u_{i\left(t-s_{i}^{i n}-p_{i}\right)}=I_{i 0}-\sum_{k=s_{i}^{o u t}}^{s_{i}^{i n}+p_{i}} d_{i(t-k)}
$$

where $I_{i t}$ denotes inventory level at stage $i$ at period $t, u_{i t}$ denotes order quantity at stage $i$ at period $t\left(u_{i t}=d_{i t}\right), s_{i}^{i n}$ denotes in-bound service time at stage $i, p_{i}$ denotes processing time at stage $i$.

The dynamics Eq. (1) can be rewritten in the following form as in Eq. (2),

$$
I_{i t}=B_{i}-d_{i}\left(t-s_{i}^{i n}-p_{i}, t-s_{o u t}^{i}\right)
$$

where $B_{i}=I_{i 0}$ denotes base-stock level of stage $i$ and $d_{i}\left(T_{1}, T_{2}\right)$ denotes demand at stage $i$ over the time interval ( $\left.\mathrm{T}_{1}, \mathrm{~T}_{2}\right]$ as follows:

$d_{i}\left(T_{1}, T_{2}\right)=d_{i\left(T_{1}+1\right)}+\cdots+d_{i\left(T_{2}\right)}$

The Eq. (2) can be derived from backward substitution. From the Eq. (2), the base-stock level $B_{i}$ to hold $I_{i t} \geq 0$ to provide $100 \%$ service is as in Eq. (3):

$$
B_{i} \geq d_{i}\left(t-s_{i}^{i n}-p_{i}, t-s_{o u t}^{i}\right)
$$

The least base-stock to satisfy the inequality (3) is as in Eq. (4):

$$
B_{i}=D_{i}\left(\tau_{i}\right) \text { where } \tau_{i}=s_{i}^{i n}+p_{i}-s_{i}^{\text {out }}
$$

\section{Expected Inventory Level}

Expected inventory level $I_{i t}$ is given as follows in Eq. (5) 


$$
\mathbb{E}_{\{t\}}\left[I_{i t}\right]=\mathbb{E}_{t}\left[B_{i}-d_{i}\left(t-s_{i}^{i n}-p_{i}, t-s_{\text {out }}^{i}\right)\right]=\mathbb{E}_{t}\left[B_{i}\right]-\mathbb{E}_{t}\left[d_{i}\left(t-s_{i}^{i n}-p_{i}, t-s_{\text {out }}^{i}\right)\right]=D_{i}\left(\tau_{i}\right)-\mu_{i} \tau_{i}
$$

For the case where demand follows normal distribution $d_{i t} \sim \mathcal{N}\left(\mu_{i}, \sigma_{i}^{2}\right)$, the problem becomes as follows in Eq. (6)

$$
\mathbb{E}_{\{t\}}\left[I_{i t}\right]=k h_{i} \sigma_{i} \sqrt{\tau_{i}}
$$

\section{Formulation}

Expanding the discussion above to multi-stage problem, the GS model to safety stock placement problem:

$\begin{array}{ll}\operatorname{minimize} & \sum_{i=1}^{N} k h_{i} \sigma_{i} \sqrt{\tau_{i}} \\ \text { subject to } & \tau_{i}=s_{i}^{\text {in }}+p_{i}-s_{i}^{\text {out }} \\ & \tau_{i} \geq 0, \\ & s_{j}^{\text {in }}-s_{i}^{\text {out }} \geq 0 \\ & s_{i}^{\text {out }} \leq T_{i}, \\ & s_{i}^{\text {out }}, s_{i}^{\text {in }} \in Z^{+}\end{array}$

where $h_{i}$ denotes unit-inventory holding cost rate at stage $i$, and $T_{i}$ denotes service level target for external customer $i \in N_{d}$.

The decision variables are service time $s_{i}^{\text {out }}$ and $s_{i}^{\text {in }}$. The objective function (7a) is the expected inventory holding cost as discussed in the equation (6). The constraint (7b) is the definition of $\tau_{i}$. Constraints (7c)-(7f) assure that the service times are feasible. The constraints (7c) assure that the net replenishment time of each stage is nonnegative. The constraints (7d) assure that the inbound service time at every stage is at least as large as the largest outbound service time quoted to the stage. The constraints (7e) assure that the outbound service times to the customer must be no greater than the required leadtime. The constraints $(7 \mathrm{f})$ assure that the service times must be nonnegative and integer.

The problem (7) is the nonlinear concave minimization problem. To solve the problem (7), typically the dynamic programming or piecewise linearization technique is applied.

\subsection{Network settings}

In this section, we present three models of supply chains: traditional supply chain, 3DPR at warehouses supply chain (3DPRW), and 3DPR at shops supply chain (3DPRS).

\section{Traditional supply chain}

In traditional supply chain, we assume that there is only one factory, and the factory is connected to $n_{w}$ warehouses. Each warehouse is connected to $n_{s}$ shops. Each stage, i.e., factory, warehouse, and shop, has inventories of $n_{p}$ different types of products, each of which is represented by a node. We let $N_{f} \subseteq N=\left\{i \mid i=1, \cdots, n_{p}\right\}$ be a factory node. We let $N_{w} \subseteq N=$ $\left\{i \mid i=n_{p}+1, \cdots, n_{p} \times\left(1+n_{w}\right)\right\}$ denote a set of warehouse nodes. We let $N_{s} \subseteq N=\left\{i \mid i=n_{p} \times\left(1+n_{w}\right)+\right.$ $\left.1, \cdots, n_{p} \times\left(1+n_{w}\right)+n_{p} \times n_{w} \times n_{s}\right\}$ denote a set of shop nodes. Note that $N_{s}$ is equivalent to $N_{d}$ described in the section 2.2. There are directed arcs all pairs between factory nodes and warehouse nodes, i.e., from $\forall i \in N_{f}$ to $\forall j \in N_{w}$. There are directed arcs all pairs between warehouse nodes and shop nodes, i.e., from $\forall i \in N_{w}$ to $\forall j \in N_{s}$. We do not consider online channel, although it is an interesting topic, and do not consider the shipment from warehouse to customers. In traditional supply chain, we assume that the product is manufactured at the factory and the factory holds product inventory. We assume that inbound lead-time from outside suppliers is identical and we let $s$ denote the inbound lead-time from outside suppliers. We assume that outbound lead-time to customer needs to be zero. Figure 2 illustrate supply chain configurations for the traditional supply chain with $n_{p}=3, n_{w}=2, n_{s}=2$. We assume that stage $i$ in factory node is quoted the same inbound service time $s_{f}^{i n}$ from material suppliers $s_{i}^{i n}=s_{f}^{i n}, \forall i \in N_{f}$ and stage $i$ quotes the same guaranteed service time $s_{f}^{\text {out }}$ to all downstream stages $s_{i}^{\text {out }}=s_{f}^{\text {out }}, \forall i \in N_{f}$. Similarly, we assume the same inbound service time $s_{w}^{\text {in }}$ and the same guaranteed service time $s_{w}^{\text {out }}$ for all stages in warehouse node, and the same inbound service time $s_{w}^{\text {in }}$ and guaranteed service time $s_{w}^{\text {out }}$ for all stages in warehouse node.

The problem can be reduced the following problem.

$$
\begin{array}{ll}
\operatorname{minimize} & k\left(n_{w} n_{s} h_{s} \sigma_{s} \sqrt{\tau_{s}}+n_{w} h_{w} \sigma_{w} \sqrt{\tau_{w}}+h_{f} \sigma_{f} \sqrt{\tau_{f}}\right) \\
\text { subject to } & \tau_{f}=s_{f}^{\text {in }}+p_{f}-s_{f}^{\text {out }} \\
& \tau_{w}=s_{w}^{\text {in }}+p_{w}-s_{w}^{\text {out }}
\end{array}
$$




$$
\begin{aligned}
& \tau_{s}=s_{s}^{\text {in }}+p_{s}-s_{s}^{\text {out }} \\
& \tau_{f}, \tau_{w}, \tau_{s} \geq 0 \\
& s_{f}^{\text {out }} \leq s_{w}^{\text {in }} \\
& S_{w}^{\text {out }} \leq s_{s}^{\text {in }} \\
& s_{s}^{\text {out }}=0 \\
& s_{f}^{\text {in }}=s_{i}
\end{aligned}
$$

We let $h_{s}, h_{w}, h_{f}$ denote the inventory holding cost for the stage in $N_{s}, N_{w}, N_{f}$ respectively. Let $\sigma_{s}, \sigma_{w}, \sigma_{f}$ denote the standard deviation of demand for the stage in $N_{s}, N_{w}, N_{f}$ respectively. Let $p_{s}, p_{w}, p_{f}$ denote the processing time for the stage in $N_{s}, N_{w}, N_{f}$ respectively. Further, for the constraint (8f)-(8g) has a single component, and thus can be reduced to $s_{f}^{\text {out }}=s_{w}^{\text {in }}$ and,$s_{w}^{\text {out }}=s_{s}^{\text {in }}$. Substituting the constraints $(8 \mathrm{~b})-(8 \mathrm{~d})$ the problem becomes as follows.

$$
\begin{array}{ll}
\text { minimize } & k\left(n_{w} n_{s} h_{s} \sigma_{s} \sqrt{s_{w}^{\text {out }}+p_{s}}+n_{w} h_{2} \sigma_{w} \sqrt{s_{f}^{\text {out }}+p_{w}-s_{w}^{\text {out }}}+h_{f} \sigma_{f} \sqrt{s_{f}^{\text {in }}+p_{f}-s_{f}^{\text {out }}}\right) \\
\text { subject to } & s_{f}^{\text {out }}, s_{w}^{\text {out }} \geq 0
\end{array}
$$

The problem has only two decision variables $s_{f}^{\text {out }}, s_{w}^{\text {out }}$ and thus can be solved easily.

The total cost is composed of three terms:

$C_{f}=C_{f}^{E}+C_{f}^{P}+C_{f}^{I}$,

where $C_{f}^{E}$ is equipment installation cost, $C_{f}^{P}$ is production cost, and $C_{f}^{I}$ is inventory holding cost. The inventory holding cost is the objective function value of the solution of the problem (8). The production cost is calculated by $c_{f}^{P}=$ $c_{f}^{p} \sum_{i \in N_{S}} \mu_{i}$, where $c_{f}^{p}$ is the unit production cost of the factory and $\sum_{i \in N_{S}} \mu_{i}$ is the total demand.

\section{DPR at warehouses supply chain}

In the 3DPRW supply chain, there is no factory node and materials are directly supplied to warehouse nodes. We assume that the product is manufactured at the warehouse after the request from shops, and each warehouse holds material inventory. We assume that inbound lead-time from outside suppliers is identical and we let $s$ denote the inbound lead-time from outside suppliers. Fig. 3 illustrate supply chain configurations for the traditional supply chain with $n_{p}=3, n_{w}=2, n_{s}=2$.

The similar discussion with the traditional supply chain case, the problem can be reduced to the following.

$$
\begin{array}{ll}
\text { minimize } & k\left(n_{w} n_{s} h_{s} \sigma_{s} \sqrt{s_{w}^{\text {out }}+p_{s}}+n_{w} h_{w} \sigma_{w} \sqrt{s+p_{w}-s_{w}^{\text {out }}}\right) \\
\text { subject to } & s_{w}^{\text {out }} \geq 0
\end{array}
$$

The problem has only one decision variables $s_{w}^{\text {out }}$ and thus can be solved easily. The cost total cost is composed of the three terms

$C_{w}=C_{w}^{E}+C_{w}^{P}+C_{w}^{I}$

where $C_{w}^{E}$ is equipment installation cost, $C_{w}^{P}$ is production cost, and $C_{w}^{I}$ is inventory holding cost. Equipment installation cost is calculated by $C_{w}^{E}=c_{w}^{E} \times n_{w}$, where $c_{w}^{E}$ is the installation cost at warehouse. Production cost is calculated as $C_{w}^{P}=$ $c_{w}^{P} \sum_{i \in N_{S}} \mu_{i}$.

\section{DPR at shops supply chain}

In the 3DPRS supply chain, there is no warehouse node and materials are directly supplied to shop nodes. We assume that the product is manufactured at the shops after request from customers, and each shop holds material inventory. Figure 4 illustrate supply chain configurations for the traditional supply chain with $n_{p}=3, n_{w}=2, n_{s}=2$.

The similar discussion with the traditional supply chain case, the inventory cost is calculated deterministically as follows:

$k n_{w} n_{s} h_{s} \sigma_{s} \sqrt{s+p_{s}}$

The cost total cost is composed of the three terms 
496

$C_{s}=C_{s}^{E}+C_{s}^{P}+C_{s}^{I}$

where $C_{s}^{E}$ is equipment installation cost, $C_{s}^{P}$ is production cost, and $C_{s}^{I}$ is inventory holding cost. Equipment installation cost is calculated by $C_{s}^{E}=c_{s}^{E} \times n_{w} \times n_{s}$, where $c_{s}^{E}$ is the installation cost at each shop. Production cost is calculated as $C_{s}^{P}=c_{s}^{P} \sum_{i \in N_{s}} \mu_{i}$.

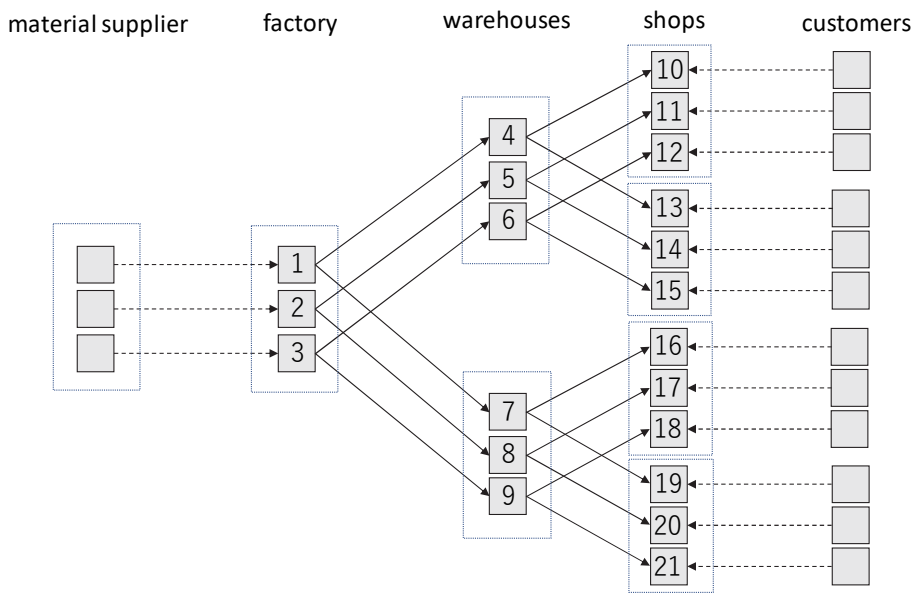

Fig. 2. An example illustrating the traditional supply chain with $n_{p}=3, n_{w}=2, n_{s}=2$

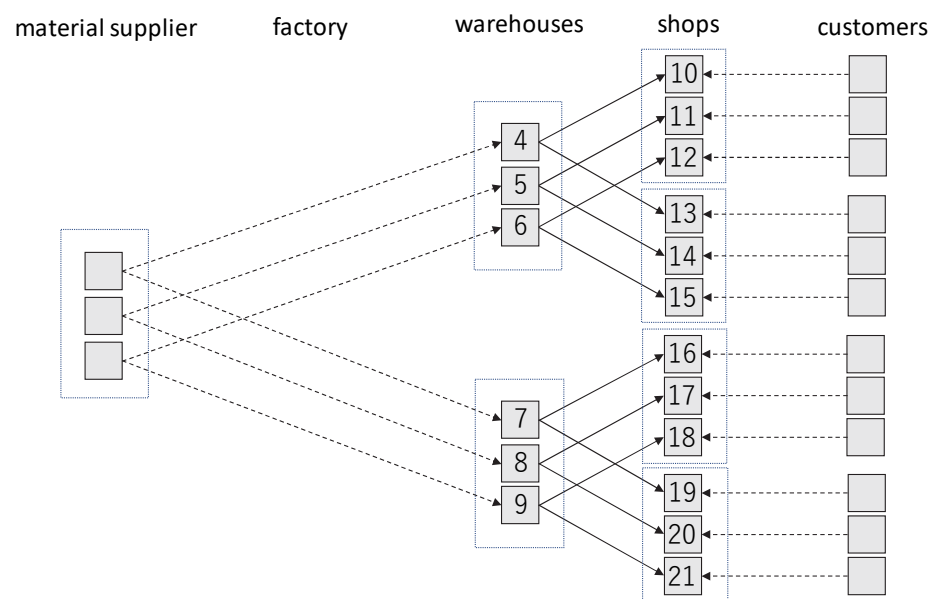

Fig. 3. An example illustrating 3DPRW with $n_{p}=3, n_{w}=2, n_{s}=2$

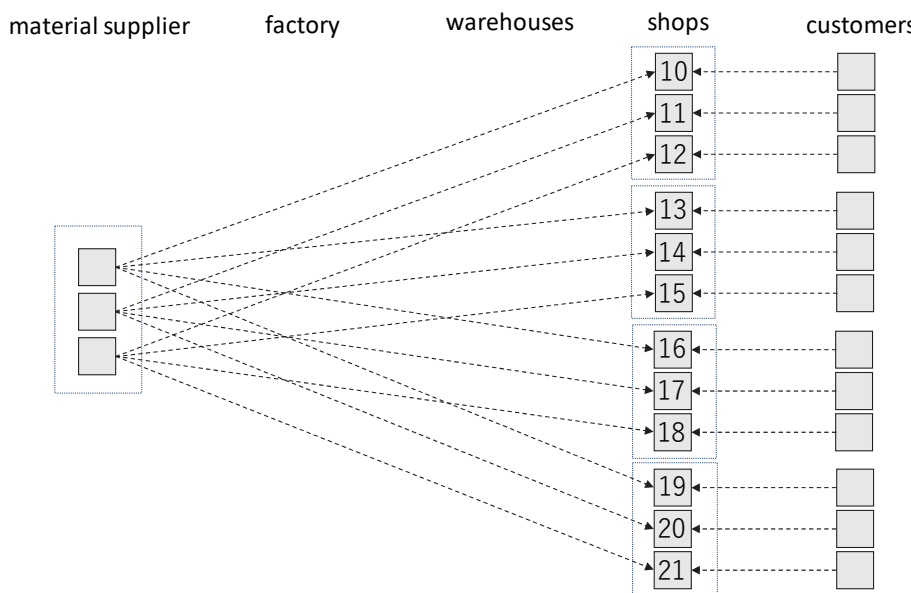

Fig. 4. An example illustrating 3DPRS with $n_{p}=3, n_{w}=2, n_{s}=2$ 


\section{Numerical examples}

\subsection{Experimental setting and datasets}

Demand follows normal distribution $d_{i} \sim N\left(\mu, \sigma^{2}\right)$ with $\mu=100, \sigma=15$. We set $n_{p}=30, n_{w}=2, n_{s}=20$. Equipment cost is $C_{f}^{E}=100,000,000, C_{w}^{E}=\left(5,000,000 \times n_{w} \times \alpha\right) \times n_{s}, C_{s}^{E}=5,000,000 \times n_{w} \times n_{s}$, where $\alpha \in[0,1]$ is the parameter to consider the economy of scale. In many supply chains, there will be some relative reduction in variability as demand streams are combined, which might incur lower equipment cost of 3DPRW than 3DPRS. We explicitly choose to let the parameter $\alpha$ to account for the economy of scale. In this experiment, we calculate the ratio of maximal demand as

$\alpha=\frac{n_{p} n_{s} \mu+k \sigma \sqrt{n_{p} n_{s}}}{n_{s} n_{w}\left(n_{p} \mu+k \sigma \sqrt{n_{p}}\right)}$.

where the numerator is the maximal total demand for 3DPRW and the denominator is the maximal total demand for 3DPRS. Unit production cost is $c_{f}^{P}=30, c_{w}^{P}=65, c_{s}^{P}=70$. We consider that the price of product is $v=100$. We assume that in the traditional supply chain, the inventory holding cost is $0.9 v$ at the factory, $0.95 v$ at warehouse, and $v$ at shops. We assume that in 3DPR at the warehouses, products are manufactured in the warehouses and the inventory holding cost is $0.5 v$ at warehouses and $v$ at shops. We assume that in 3DPR at the shops, products are manufactured in the shops after the purchase request, and the inventory holding cost is $0.55 \mathrm{v}$ at shops.

The model described above is implemented coded in MATLAB run on the personal computer with Intel (R) Core (TM) i7$8700 \mathrm{CPU}, 3.20 \mathrm{GHz}, 3.19 \mathrm{GHz}$ with $32.0 \mathrm{~GB}$ memory.

\subsection{Results}

Theobtained cost is summarized as in Table 2. The obtained net replenishment timeis summarized as in table 3. The cost of the traditional supply chain is thelowest among three supply chains. While the inventory cost of the traditionalsupply chain is the highest, the equipment installation cost and the productioncost are the lowest. The result indicates that the 3DPRW and 3DPRS could beexpensive as the number of robots to be installed is high. Therefore, although automation is attractive in many industries, the 3DPR cannot fully bereplaced with the traditional manufacturing equipment.

The inventory cost of 3DPRS is the lowest, as the number of stock points is the smallest (one) and the inventory holding cost is also cheap. This result indicates that the 3DPRS could be attractive option if the inventory related cost, such as the product value $v$, the standard deviation $\sigma$ and the number of products $n_{p}$. This will lead to the sensitivity analysis described in the section 4.3 .

Table 2

Obtained cost for the three supply chain models

\begin{tabular}{lccc}
\hline Item & Traditional & 3DPRW & 3DPRS \\
\hline Equipment installation cost & $100,000,000$ & $198,909,710$ & $200,000,000$ \\
Production cost & $24,000,000$ & $52,000,000$ & $56,000,000$ \\
Inventory cost & $55,869,407$ & $14,937,206$ & $39,200,000$ \\
\hline Total Cost & $179,869,407$ & $254,829,710$ & $270,937,206$ \\
\hline
\end{tabular}

Table 3

Obtained net replenishment time the three supply chain models

\begin{tabular}{lccc}
\hline \multicolumn{1}{c}{ Item } & Traditional & 3DPRW & 3DPRS \\
\hline Inventory at factory & 11 & - & - \\
Inventory at warehouses & 0 & 0 & - \\
Inventory at shops & 3 & 5 & 3 \\
\hline
\end{tabular}

\subsection{Sensitivity analysis}

In this section, we have conducted a sensitivity analysis, and understand which supply chain model is better under different parameter settings. We change the parameters of the product value $v$, the standard deviation $\sigma$, and the number of products $n_{p}$. All these parameters are relevant to the innovative-functional product segmentation. For the innovative product, $v$ and $\sigma$ are relatively high. Also, for the innovative product, we assume that the customer is willing to customize the product as they want. The result of sensitivity analysis with respect to the product value $v$ is presented in the Table 4 . For $v \geq 300$, the 3DPRW is lower than the traditional supply chain, and for $v \geq 400$ the 3DPRS is lower than the traditional supply chain. The result indicates that as the value of product is the cost of 3DPRW and 3DPRS are relatively lower than the cost of the traditional supply chain. The result of sensitivity analysis with respect to the standard deviation $\sigma$ is presented in the table 5. For $v \geq 300$, the 3DPRW is lower than the traditional supply chain, and for $v \geq 400$ the 3DPRS is lower than the 
traditional supply chain. The result indicates that as the value of product is the cost of 3DPRW and 3DPRS are relatively lower than the cost of the traditional supply chain. The result of sensitivity analysis with respect to the product value $v$ is presented in the table 6. For $v \geq 300$, the 3DPRW is lower than the traditional supply chain, and for $v \geq 400$ the 3DPRS is lower than the traditional supply chain. The result indicates that as the value of product is the cost of 3DPRW and 3DPRS are relatively lower than the cost of the traditional supply chain. Finally, the values $v, \sigma, n_{p}$ are changed simultaneously from smaller values to larger values. The result of sensitivity analysis is summarized as in Table 7 . The results indicate that the increase of cost is smaller for the 3DPRW and 3DPRS models, whereas the cost of traditional supply chains increase sharply.

Table 4

A sensitivity analysis with respect to the product value $v$.

\begin{tabular}{cccc}
\hline$v$ & Traditional & 3DPRW & 3DPRS \\
\hline 100 & $179,869,407$ & $254,829,710$ & $270,937,206$ \\
200 & $235,738,814$ & $258,749,710$ & $285,874,412$ \\
300 & $291,608,221$ & $262,669,710$ & $300,811,618$ \\
400 & $347,477,628$ & $266,589,710$ & $315,748,824$ \\
500 & $403,347,035$ & $270,509,710$ & $330,686,030$ \\
\hline
\end{tabular}

Table 5

A sensitivity analysis with respect to the standard deviation $\sigma$

\begin{tabular}{cccc}
\hline$\sigma$ & Traditional & 3DPRW & 3DPRS \\
\hline 10 & $179,869,407$ & $254,829,710$ & $270,937,206$ \\
20 & $235,738,814$ & $258,749,710$ & $285,874,412$ \\
30 & $291,608,221$ & $262,669,710$ & $300,811,618$ \\
40 & $347,477,628$ & $266,589,710$ & $315,748,824$ \\
50 & $403,347,035$ & $270,509,710$ & $330,686,030$ \\
\hline
\end{tabular}

Table 6

A sensitivity analysis with respect to the number of products $n_{p}$

\begin{tabular}{cccc}
\hline$n_{p}$ & Traditional & 3DPRW & 3DPRS \\
\hline 20 & $107,986,940$ & $202,195,455$ & $207,093,720$ \\
200 & $179,869,407$ & $254,829,710$ & $270,937,206$ \\
300 & $219,804,110$ & $282,988,646$ & $306,405,809$ \\
400 & $259,738,814$ & $311,067,425$ & $341,874,412$ \\
500 & $299,673,517$ & $339,108,741$ & $377,343,015$ \\
1000 & $499,347,035$ & $479,110,522$ & $554,686,030$ \\
3600 & $1,537,649,327$ & $1,206,301,638$ & $1,476,869,710$ \\
\hline
\end{tabular}

Table 7

A sensitivity analysis with respect to the product value $\left(\mathrm{v}, \sigma, n_{p}\right)$

\begin{tabular}{cccc}
\hline$\left(v, \sigma, n_{p}\right)$ & Traditional & 3DPRW & 3DPRS \\
\hline$(100,10,20)$ & $110,386,940$ & $209,074,943$ & $212,693,720$ \\
$(200,20,40)$ & $154,295,525$ & $221,519,823$ & \\
$(300,30,60)$ & 265,247399 & $238,834,248$ & $234,349,764$ \\
$(400,40,80)$ & $476,764,205$ & $263,291,905$ & \\
$(500,50,100)$ & $822,367,588$ & $297,212,685$ & $340,398,119$ \\
\end{tabular}

All these results indicate that the functional product with lower product value, smaller demand uncertainty and smaller need for the customization, the traditional supply chain is still an attractive option. However, for innovative products, 3DPR could be an attractive option. Typically, as the $80 \% / 20 \%$ rule goes, the most popular $20 \%$ of SKUs account for $80 \%$ of the volume. These items should be manufactured by the traditional supply chain as a push option. On the other hand, the remaining $80 \%$ of SKUs in the so-called "long-tail" of the curve, the 3DPR may be replaced with the traditional supply chain. Finally, for the future, as the cost of robots and the manufacturing is expected to be cheaper, the opportunity of using 3DPR becomes much higher.

\section{Conclusion}

Many companies are facing the challenge that customers are demanding highly customized products and services at an acceptable cost. Diverse needs and dramatic shortening of product life cycles lead to a need for an effective product variety management. The efficient design of multiple supply chains is a major challenge for many companies, given a number of factors and interactions involved. An important issue is installing 3D printers and robotics at warehouses or at shops.

In this paper, we study the location of 3DPR in the supply chain. We present and compare three models of supply chains: Traditional supply chain; 3DPR at warehouse; 3DPR at shop. These models are compared by the production cost, equipment installation cost, and inventory cost for safety-stock. The inventory cost for safety-stock is obtained by the guaranteedservice model proposed by Graves and Willems (2000). We present a practical case study motivated from a real-world 
apparel company. We discuss the three models under the different parameter settings, comparing the obtained total cost. The experimental considers multiple factors which influence optimal supply chain design/configurations to use. Furthermore, the results indicate that the higher product value, higher demand variability, larger the number of products should be supplied by the 3DPR. For future works, the decision of the number of robots can be incorporated. This can be considered by the guaranteed service model with capacity constraints proposed by Graves and Schoenmeyr (2016). This model considers the inner queue at each stage, and the length of processing time can be controlled by the number of robots installed at each stage. Another related topic is the configuration of multiple supply chains, as the results indicated that the ideal supply chain is different by product types. Therefore, one-size-fits-all supply chain is no longer effective for the most of the supply chain. The postponement or the delayed differentiation can be also considered explicitly. The shipment from warehouse to customers should also be considered, as the increase of e-commerce and omnichannel retailing.

\section{References}

Berman, B. (2012). 3-D printing: The new industrial revolution. Business Horizons, 55(2), 155-162.

Billington, C., Callioni, G., Crane, B., Ruark, J. D., Rapp, J. U., White, T., \& Willems, S. P. (2004). Accelerating the profitability of Hewlett-Packard's supply chains. Interfaces, 34(1), 59-72.

Bossert, J. M., \& Willems, S. P. (2007). A periodic-review modeling approach for guaranteed service supply chains. Interfaces, 37(5), 420-436.

Christopher, M., \& Ryals, L. J. (2014). The supply chain becomes the demand chain. Journal of Business Logistics, 35(1), 29-35.

Clark, A. J., \& Scarf, H. (1960). Optimal policies for a multi-echelon inventory problem. Management Science, 6(4), 475490.

Doherty, D. (2012). Downloading infringement: patent law as a roadblock to the 3D printing revolution. Harv. JL \& Tech., $26,353$.

Eruguz, A. S., Sahin, E., Jemai, Z., \& Dallery, Y. (2016). A comprehensive survey of guaranteed-service models for multiechelon inventory optimization. International Journal of Production Economics, 172, 110-125.

Eyers, D., \& Dotchev, K. (2010). Technology review for mass customisation using rapid manufacturing. Assembly Automation, 30(1), 39-46.

Fandel, G., Gulledge, T., \& Jones, A. (Eds.). (2012). Operations Research in Production Planning and Control: Proceedings of a Joint German/US Conference, Hagen, Germany, June 25-26, 1992. Under the Auspices of Deutsche Gesellschaft Für Operations Research (DGOR), Operations Research Society of America (ORSA). Springer Science \& Business Media.

Farasyn, I., Humair, S., Kahn, J. I., Neale, J. J., Rosen, O., Ruark, J., ... \& Willems, S. P. (2011). Inventory optimization at Procter \& Gamble: Achieving real benefits through user adoption of inventory tools. Interfaces, 41(1), 66-78.

Fawcett, S. E., \& Waller, M. A. (2014). Supply chain game changers?mega, nano, and virtual trends?and forces that impede supply chain design (ie, building a winning team). Journal of Business Logistics, 35(3), 157-164.

Fisher, M. L. (1997). What is the right supply chain for your product?. Harvard Business Review, 75, 105-117.

Funaki, K. (2012). Strategic safety stock placement in supply chain design with due-date based demand. International Journal of Production Economics, 135(1), 4-13.

Gao, W., Zhang, Y., Ramanujan, D., Ramani, K., Chen, Y., Williams, C. B., ... \& Zavattieri, P. D. (2015). The status, challenges, and future of additive manufacturing in engineering. Computer-Aided Design, 69, 65-89.

Gebler, M., Uiterkamp, A. J. S., \& Visser, C. (2014). A global sustainability perspective on 3D printing technologies. Energy Policy, 74, 158-167.

Graves, S. C., \& Schoenmeyr, T. (2016). Strategic safety-stock placement in supply chains with capacity constraints. Manufacturing \& Service Operations Management, 18(3), 445-460.

Graves, S. C., \& Willems, S. P. (2000). Optimizing strategic safety stock placement in supply chains. Manufacturing \& Service Operations Management, 2(1), 68-83.

Graves, S. C., \& Willems, S. P. (2003). Supply chain design: safety stock placement and supply chain configuration. Handbooks in operations research and management science, 11, 95-132.

Graves, S. C., \& Willems, S. P. (2005). Optimizing the supply chain configuration for new products. Management Science, 51(8), 1165-1180.

Graves, S. C., \& Willems, S. P. (2008). Strategic inventory placement in supply chains: Nonstationary demand. Manufacturing \& Service Operations Management, 10(2), 278-287.

Holmstrom, J., Partanen, J., Tuomi, J., \& Walter, M. (2010). Rapid manufacturing in the spare parts supply chain: alternative approaches to capacity deployment. Journal of Manufacturing Technology Management, 21(6), 687-697.

Humair, S., Ruark, J. D., Tomlin, B., \& Willems, S. P. (2013). Incorporating stochastic lead times into the guaranteed service model of safety stock optimization. Interfaces, 43(5), 421-434.

Inderfurth (1993) prosed a model to incorporate stochastic lead-times,

Khajavi, S. H., Partanen, J., \& Holmstrom, J. (2014). Additive manufacturing in the spare parts supply chain. Computers in Industry, 65(1), 50-63.

Klosterhalfen, S. T., Minner, S., \& Willems, S. P. (2014). Strategic safety stock placement in supply networks with static dual supply. Manufacturing \& Service Operations Management, 16(2), 204-219.

Li, H., \& Womer, K. (2008). Modeling the supply chain configuration problem with resource constraints. International Journal of Project Management, 26(6), 646-654. 
Li, P., \& Chen, H. (2012). Optimal (R, nQ) policies for serial inventory systems with guaranteed service. In Operations Research Proceedings 2011 (pp. 439-444). Springer, Berlin, Heidelberg.

Lipson, H., \& Kurman, M. (2013). Fabricated: The new world of $3 D$ printing. John Wiley \& Sons.

Mellor, S., Hao, L., \& Zhang, D. (2014). Additive manufacturing: A framework for implementation. International Journal of Production Economics, 149, 194-201.

Moncayo-Martínez, L. A., \& Zhang, D. Z. (2013). Optimising safety stock placement and lead time in an assembly supply chain using bi-objective MAX-MIN ant system. International Journal of Production Economics, 145(1), 18-28.

Moncayo-Martínez, L. A., Reséndiz-Flores, E. O., Mercado, D., \& Sánchez-Ramírez, C. (2014). Placing safety stock in logistic networks under guaranteed-service time inventory models: An application to the automotive industry. Journal of applied research and technology, 12(3), 538-550.

Neale, J. J., \& Willems, S. P. (2009). Managing inventory in supply chains with nonstationary demand. Interfaces, 39(5), 388-399.

Ni, W., \& Shu, J. (2015). Trade-off between service time and carbon emissions for safety stock placement in multi-echelon supply chains. International Journal of Production Research, 53(22), 6701-6718.

Petrick, I. J., \& Simpson, T. W. (2013). 3D printing disrupts manufacturing: how economies of one create new rules of competition. Research-Technology Management, 56(6), 12-16.

Rambau, J., \& Schade, K. (2010). The stochastic guaranteed service model with recourse for multi-echelon warehouse management. Electronic Notes in Discrete Mathematics, 36, 783-790.

Rayna, T., \& Striukova, L. (2016). From rapid prototyping to home fabrication: How 3D printing is changing business model innovation. Technological Forecasting and Social Change, 102, 214-224.

Rayna, T., Striukova, L., \& Darlington, J. (2015). Co-creation and user innovation: The role of online 3D printing platforms. Journal of Engineering and Technology Management, 37, 90-102.

Rideout, B. (2011). Printing the impossible triangle: the copyright implications of three-dimensional printing. Journal of Business Entrepreneurship \& Leadership, 5, 161.

Rogers, H., Baricz, N., \& Pawar, K. S. (2016). 3D printing services: classification, supply chain implications and research agenda. International Journal of Physical Distribution \& Logistics Management, 46(10), 886-907.

Sasson, A., \& Johnson, J. C. (2016). The 3D printing order: variability, supercenters and supply chain reconfigurations. International Journal of Physical Distribution \& Logistics Management, 46(1), 82-94.

Schoenmeyr, T. T. I. (2008). Strategic inventory placement in multi-echelon supply chains: three essays (Doctoral dissertation, Massachusetts Institute of Technology).

Schoenmeyr, T., \& Graves, S. C. (2009). Strategic safety stocks in supply chains with evolving forecasts. Manufacturing \& Service Operations Management, 11(4), 657-673.

Simchi-Levi, D. (2010). Operations rules: delivering customer value through flexible operations. Mit Press.

Sitompul, C., Aghezzaf, E. H., Dullaert, W., \& Landeghem, H. V. (2008). Safety stock placement problem in capacitated supply chains. International Journal of Production Research, 46(17), 4709-4727.

Sodhi, M., \& Tang, C. S. (2017). Supply chains built for speed and customization. MIT Sloan Management Review, 58(4), 58419.

Tang, C. S., \& Veelenturf, L. P. (2019). The Strategic Role of Logistics in the Industry 4.0 Era. Forthcoming in: Transportation Research Part E: Logistics and Transportation Review, 129, 1-11.

Tian, F., Willems, S. P., \& Kempf, K. G. (2011). An iterative approach to item-level tactical production and inventory planning. International Journal of Production Economics, 133(1), 439-450.

Topan, E., Eruguz, A. S., Ma, W., van der Heijden, M. C., \& Dekker, R. (2020). A review of operational spare parts service logistics in service control towers. European Journal of Operational Research, 282(2), 401-414.

Wieland, B., Mastrantonio, P., Willems, S. P., \& Kempf, K. G. (2012). Optimizing inventory levels within Intel's channel supply demand operations. Interfaces, 42(6), 517-527.

Yoon, H. S., Lee, J. Y., Kim, H. S., Kim, M. S., Kim, E. S., Shin, Y. J., Chu, W. S., \& Ahn, S. H. (2014). A comparison of energy consumption in bulk forming, subtractive, and additive processes: Review and case study. International Journal of Precision Engineering and Manufacturing-Green Technology, 1(3), 261-279.

You, F., \& Grossmann, I. E. (2008). Mixed-integer nonlinear programming models and algorithms for large-scale supply chain design with stochastic inventory management. Industrial \& Engineering Chemistry Research, 47(20), $7802-7817$.

You, F., \& Grossmann, I. E. (2011). Stochastic inventory management for tactical process planning under uncertainties: MINLP models and algorithms. AIChE Journal, 57(5), 1250-1277.

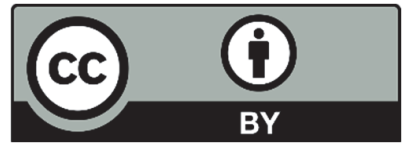

(C) 2021 by the authors; licensee Growing Science, Canada. This is an open access article distributed under the terms and conditions of the Creative Commons Attribution (CC-BY) license (http://creativecommons.org/licenses/by/4.0/). 